\title{
Unconscious Priming of Focused Attention Reduces the Attention Deficits of ADHD Patients
}

\author{
Elaheh Hosseini, Otmar Bock, Monika Thomas \\ Institute of Physiology and Anatomy, German Sport University Cologne, Cologne, Germany \\ Email: e.hosseini@dshs-koeln.de, bock@dshs-koeln.de, thomas@dshs-koeln.de
}

Received 29 April 2016; accepted 5 June 2016; published 8 June 2016

Copyright (C) 2016 by authors and Scientific Research Publishing Inc.

This work is licensed under the Creative Commons Attribution International License (CC BY). http://creativecommons.org/licenses/by/4.0/

(c) (i) Open Access

\begin{abstract}
We have shown before that attention deficit hyperactivity disorder (ADHD) children suffer from deficits of sustained attention, while divided, selective and distributed attention is largely spared. The present study explores whether these deficits can be ameliorated by unconscious priming of attention. Sixty children diagnosed with ADHD participated, their age ranged between eight and twelve years. Participants were primed with the scrambled sentence task: under the pretext of a language comprehension task, they were exposed to words referring to focused attention (group "focused") or scattered attention (group "scattered"), or were not exposed to attention-related words (group "control"). All three groups were then assessed with the same battery of attention tests used in our earlier study. We found that compared to the "control" group, performance was higher in the "focused" group on tests of sustained, divided and distributed attention, and was lower in the "scattered" group on all four tests. From this we conclude that unconscious priming can modify the attention of ADHD children, and that this modification extends to the one attention component that is most affected by ADHD. Unconscious priming might therefore be an expedient supplementary method for ADHD treatment, as it can be administered at virtually no cost anytime, anywhere.
\end{abstract}

\section{Keywords}

ADHD, Therapy, Scrambled Sentence Task, Attention Component

\section{Introduction}

Attention-deficit hyperactivity disorder (ADHD) is one of the most common neurobehavioral disorders of 
childhood, affecting 5\% - 10\% of school aged children (Faraone, Sergeant, Gillberg, \& Biederman, 2003; Wehmeier, Schacht, \& Barkley, 2010). It is characterized by impairments of attention, working memory and social skills, which may persist throughout the whole lifespan (Barkley, 2006; Hervey, Epstein, \& Curry, 2004; Weisler, 2004). Attention is thought to consist of four components, sustained, divided, selective and distributed attention (Kerns \& Mateer, 1996; Mirsky, Anthony, Duncan, Ahearn, \& Kellam, 1991a; Sturm, Willmes, Orgass, \& Hartje, 1997), and not all of them might be affected by ADHD to the same degree. Indeed, when all four components were assessed in the same sample of ADHD children and age-matched controls, only sustained attention was significantly degraded by ADHD; divided, selective and distributed attention was not affected (Bock and Hosseini, under review).

ADHD therapy typically consists of medication and one or more of sports, sleep, behavioral and social therapy. The present study explores the utility of yet another approach, unconscious priming, as a possible supplementary therapeutic method. Unconscious priming is an established procedure for activating a desired mental state in individuals without their awareness. It is often delivered by the scrambled sentence task (Bargh, Chen, \& Burrows, 1996): under the pretext of a word fluency test, participants are exposed to words that denote the desired mental state, e.g., a positive or negative attitude towards old age (Bock, Grigorova, \& Ilieva, 2013; Levy, Hausdorff, Hencke, \& Wei, 2000), a large or narrow width of visuo-spatial processing (Bock \& Beurskens, 2010) or respect for a moral authority (Ahmad \& Salsa, 2011). Although participants are not aware of those words being used, their subsequent behavior changes as if the words have indeed activated the desired mental state. As an example, when older workers of a goods receiving department were primed for a positive attitude towards old age, they subsequently performed a parcel verification task faster than their age-matched unprimed colleagues, with no loss of accuracy (Kirchner, Völker, \& Bock, 2015). Unconscious priming is more effective than conscious priming (Daza, Ortells, \& Fox, 2002; Draine \& Greenwald, 1998; Merikle \& Joordens, 1997), probably because participants can’t as easily set up psychological defenses against it.

The present study uses the scrambled sentence task to deliver words denoting "focused attention" to one group of ADHD children, words denoting "scattered attention" to a second group, and no attention-related words to a control group. The purpose of this work was to scrutinize unconscious priming as a possible supplementary ADHD treatment that would be virtually cost-free and could be applied virtually anytime, anywhere. To date, no study has examined whether priming techniques are useful for children with ADHD.

\section{Method}

Sixty children diagnosed with ADHD volunteered for the experiment. The diagnosis was made by a qualified child psychiatrist, using established DSM IV-based procedures such as the Child Behavior Checklist, the Diagnostic Interview Schedule for Children (DISC) and the parent and teacher questionnaires of the Conners test. Participants were 8 - 12 years old $(10.10 \pm 1.1)$, 5 were female. All signed an informed consent statement to this study, which was pre-approved by the Ethics Committee of the German Sport University.

The scrambled sentence task was administered to all participants according to procedures in literature. Under the pretext of word fluency test, participants were given a set of five words and had to choose four words to make a meaningful sentence, without modifying any word. The procedure was then repeated until 20 sets of five words have been dealt with or 15 minutes expired, whichever came first. All children completed the 20 sets within the allotted time. Twenty participants were randomly assigned to group "focused"; unbeknownst to them, one word in each set denoted focused attention ("persevere, pay attention, vigilantly, concentration, attentively, perseverance, tirelessly, insist, resistant, unflustered, staunchly, endure, prompt, constantly, stable, tenacity, continuous, stay, patient and careful"). Twenty other participants were assigned to group "scattered", with one word in each set denoting scattered attention ("distract, changeable, digress, confuse, incidental, disorientation, mess, irritated, fleetingly, fidgety, arbitrarily, erratic, interrupt, featureless, forget, any, mistake, coincidently, carelessly and diversion"). The remaining 20 participants formed the control group with no words referring to attention.

Immediately following the scrambled sentence task, all participants were assessed with a battery of attention tests, administered in balanced order. We have used the same battery in an earlier study about the effects of old age, and one about the effects of ADHD (Bock and Hosseini, under review).

Sustained attention was measured with a computerized version of the $\mathrm{d} 2$ test. A series of nine items was

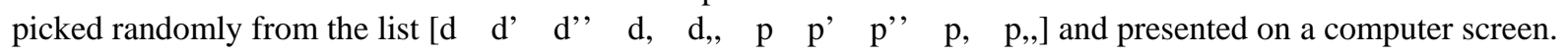


A pointer appeared below the leftmost item, and subjects had to press one of two keys depending on whether that item was or was not d'". The pointer then advanced one item, etc., until all nine items were responded to. A new series of nine items then appeared, etc., until 6 minutes expired. Outcome measure was the number of correctly minus the number of incorrectly processed items within 6 minutes.

Divided attention was measured by combining the $\mathrm{d} 2$ test with a reaction-time test (dual task). While the $\mathrm{d} 2$ task was performed once more, a red line appeared at the bottom of the screen at randomly selected intervals of 2 to $8 \mathrm{~s}$, prompting subjects to press a pedal with their right foot. Foot reaction time (RT) was registered with a resolution of about $8 \mathrm{~ms}$. As a control, foot reaction time was registered once more for three minutes without a concurrent d2-task. We then calculated the dual-task costs of each task as $\left(\mathrm{d} 2_{\text {single }}-\mathrm{d} 2_{\text {dual }}\right) / \mathrm{d} 2_{\text {single }}$ and $\left(\mathrm{RT}_{\text {dual }}-\right.$ $\left.\mathrm{RT}_{\text {single }}\right) / \mathrm{RT}_{\text {single, }}$, respectively; in either case, higher scores represent higher costs. The outcome measure was DTC, the mean dual-task costs across both tasks. This is a commonly used metric which disambiguates task demand from task priority.

Selective attention was assessed by the precue test. A circle of $0.74 \mathrm{~cm}$ diameter was presented at a central point on the screen. $500 \mathrm{~ms}$ later, a leftward pointing arrow of $1.11 \mathrm{~cm}$ length was presented to the left of the center, followed after $600-1200 \mathrm{~ms}$ by a target circle of $0.74 \mathrm{~cm}$ on the left side of the screen. Alternatively, a rightward pointing arrow was presented to the right of the center, followed by a target circle on the right side of the screen. As a third alternative, both arrows were presented concurrently and were followed with equal probability by a target circle on the left or right side of the screen. One of these three alternatives was randomly selected on each trial. Subjects were instructed to press the "spacebar" key as soon as the target circle appeared, irrespective of the target's location. Outcome measure was the difference between mean reaction time on trials with two and those with one arrow.

Distributed attention was determined with the trail-making test. Participants stood in front of a vertical panel $84 \mathrm{~cm}$ wide and $119 \mathrm{~cm}$ high, on which 25 circles numbered 1 - 25, were randomly presented. They drew lines to connect the circles in ascending order, starting with circle 1 and ending with circle 25, and were instructed to complete this task as quickly and accurately as possible. When they made a mistake, they had to return to the last correct circle and continue from there. In a control condition, all odd-numbered circles were presented in ascending order at the top, and all even-numbered ones in ascending order at the bottom of the panel. The length of a straight-line path connecting all numbers in ascending order was 2.07 times longer in the main than in the control condition, and outcome measure therefore was the completion time of the main minus 2.07 times that of the control condition.

\section{Results}

Figures 1(a)-(d) illustrate the outcomes of all four attention tests, separately for the three priming groups. Note that high scores in the $\mathrm{d} 2$ and in the precue test denote good performance, while high scores in the dual-task and in the trail-making test denote poor performance. Figure 1 therefore shows performance to decrease consistently from group "focused" to group "control" to group "scattered". This observation was confirmed by one-way analyses of variance for the $\mathrm{d} 2$ test $(\mathrm{F}(2,57)=11.06, p<0.001)$, the dual-task test $(\mathrm{F}(2,57)=11.29, p<0.001)$, the precue test $(\mathrm{F}(2,57)=9.21, p<0.001)$ and the trail-making test $(\mathrm{F}(2,57)=24.36 ; p<0.001)$. Post-hoc decomposition by Fisher's LSD revealed significant differences between all three groups in all four tests $(p<$ $0.001)$, except between, "focused" and "control" in the precue test $(p>0.05)$.

\section{Discussion}

To our knowledge, this study is the first to show that in children diagnosed with ADHD, attention can be modified by unconscious priming. The children's performance on three of four attention components was significantly improved by priming for focused attention, while performance on all four components was significantly degraded by priming for scattered attention. This outcome documents once more that unconscious priming is a reliable technique for changing participants' mental state, in this case, for changing their attention focus. The outcome further shows that the effects of priming were not specific for the participants' deficits which, according to an earlier study (Bock and Hosseini, under review), is limited to a single attention component: sustained attention. However, this lack of specificity doesn't argue against priming as a therapeutic measure, since there is no harm when therapy improves more than only the degraded function. 


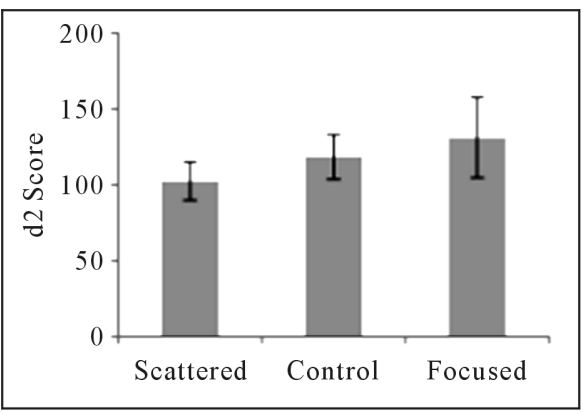

(a)

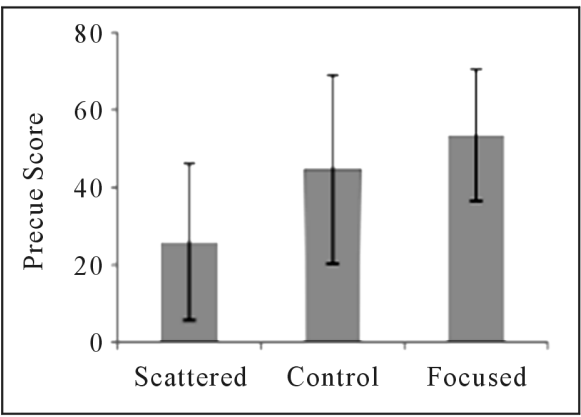

(c)

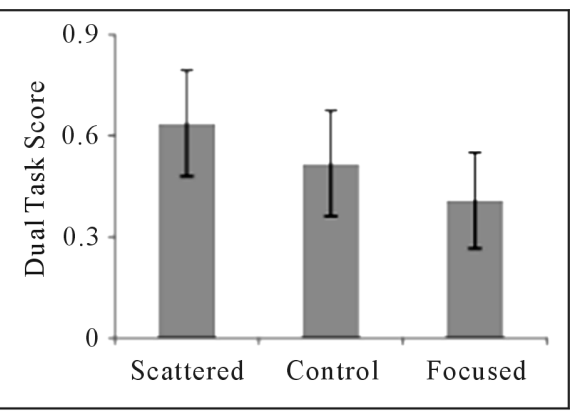

(b)

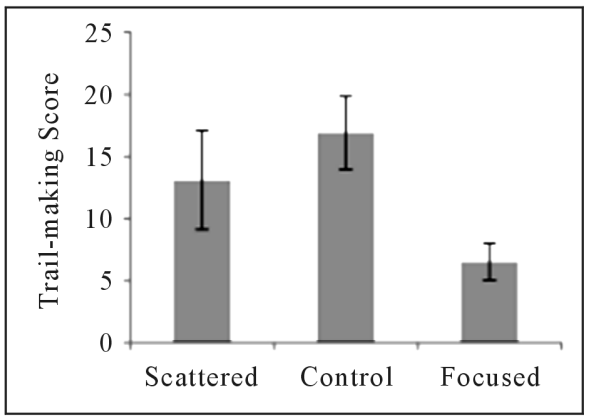

(d)

Figure 1. Scores of the four attention tests administered to ADHD children. Blocks represent group means and error bars between-subject standard deviations. Note that better performance is reflected by higher scores in (a) and (c), but by lower scores in (b) and (d). Thus, all four graphs show performance to improve from the scattered to the control to the focused group.

It remains to be determined for how long the effects of priming last after delivery, but they seem to linger on for some time, as we observed them during a testing session of about 15 minutes duration. Unconscious priming might therefore indeed be a feasible therapeutic intervention for ADHD children, supporting other treatment types. It would not be necessary to deliver the attention-focusing words by the scrambled sentence task; the words might as well appear in reading assignments, teachers' instructions or even be embedded in computer games. As an example, a computer game could display the hint "focus on the green aliens: exactly when do they shoot?" to prime the child with the words "focus" and "exactly". A main advantage of unconscious priming as a supplementary ADHD treatment is its ubiquitous availability: it can be delivered virtually anytime and anywhere, with no need for professional assistance.

\section{Acknowledgements}

This work was supported by a fellowship of the German Academic Research Service to E.H. (PIN: 91540559).

\section{References}

Ahmad, A. M., \& Salsa, O. (2011). Implicit Influences of Christian Religious Representations on Dictator and Prisoner's Dilemma Game Decisions. The Journal of Socio-Economics, 40, 242-246. http://dx.doi.org/10.1016/j.socec.2010.12.013

Bargh, J. A., Chen, M., \& Burrows, L. (1996). Direct Effects of Trait Construct and Stereotype Activation on Action. Journal of Personality and Social Psychology, 71, 230-244. http://dx.doi.org/10.1037/0022-3514.71.2.230

Barkley, R. A. (2006). Attention-Deficit Hyperactivity Disorder: A Handbook for Diagnosis and Treatment. New York: Guliford Press.

Bock, O., \& Beurskens, R. (2010). Effects of a Visual Distracter Task on the Gait of Elderly versus Young Persons. Current Gerontology and Geriatrics Research, 7, 651718.

Bock, O., Grigorova, V., \& Ilieva, M. (2013). Double-Step Adaptation of Saccadic Eye Movements Is Influenced by Priming 
with Age Stereotypies. Psychology, 4, 1014-1017. http://dx.doi.org/10.4236/psych.2013.412147

Daza, M. T., Ortells, J. J., \& Fox, E. (2002). Perception without Awareness: Further Evidence from a Stroop Priming Task. Perception \& Psychophysics, 64, 1316-1324. http://dx.doi.org/10.3758/BF03194774

Draine, S. C., \& Greenwald, A. G. (1998). Replicable Unconscious Semantic Priming. Journal of Experimental Psychology: General, 127, 286-303. http://dx.doi.org/10.1037/0096-3445.127.3.286

Faraone, S. V., Sergeant, J., Gillberg, C., \& Biederman, J. (2003). The Worldwide Prevalence of ADHD: Is It an American Condition? World Psychiatry, 2, 104-113.

Hervey, A. S., Epstein, J. N., \& Curry, J. F. (2004). Neuropsychology of Adults with Attention-Deficit/Hyperactivity Disorder: A Meta-Analytic Review. Neuropsychology, 18, 485-503. http://dx.doi.org/10.1037/0894-4105.18.3.485

Kerns, K. A., \& Mateer, C. A. (1996). Walking and chewing gum: The Impact of Attentional Capacity on Everyday Activities. Delray Beach, FL: Gr/St. Lucie Press.

Kirchner, C., Völker, I., \& Bock, O. (2015). Priming with Age Stereotypes Influences the Performance of Elderly Workers. Psychology, 6, 133-137. http://dx.doi.org/10.4236/psych.2015.62012

Levy, B., Hausdorff, J. M., Hencke, R., \& Wei, J. Y. (2000). Reducing Cardiovascular Stress with Positive Self-Stereotypes of Aging. Journals of Gerontology Series B: Psychological Sciences and Social Sciences, 55, 205-213. http://dx.doi.org/10.1093/geronb/55.4.P205

Merikle, P. M., \& Joordens, S. (1997). Parallels between Perception without Attention and Perception without Awareness. Consciousness and Cognition, 6, 219-236. http://dx.doi.org/10.1006/ccog.1997.0310

Mirsky, A. P., Anthony, B. J., Duncan, C. C., Ahearn, M. B., \& Kellam, S. G. (1991a). Analysis of the Elements of Attention: A Neuropsychological Approach. Neuropsychology Review, 2, 109-145. http://dx.doi.org/10.1007/BF01109051

Sturm, W., Willmes, K., Orgass, B., \& Hartje, W. (1997). Do Specific Attention Deficits Need Specific Training? Neuropsychological Rehabilitation, 7, 81-103. http://dx.doi.org/10.1080/713755526

Wehmeier, P. M., Schacht, A., \& Barkley, R. A. (2010). Social and Emotional Impairment in Children and Adolescents with ADHD and the Impact on Quality of Life. Journal of Adolescent Health, 46, 209-217. http://dx.doi.org/10.1016/j.jadohealth.2009.09.009

Weisler, R. H. (2004). Adult Attention Deficit Hyperactivity Disorder. Child and Adolescent Psychopharmacology News, 9, 1-7. http://dx.doi.org/10.1521/capn.9.8.1.64793 